\title{
Analysis of Using Barrier Options to the Formation of New Structured Products
}

\author{
Vincent Šoltés \\ Professor, Technical University of Košice, Faculty of Economics \\ Email: vincent.soltes@tuke.sk

\section{Monika Harčariková*} \\ Corresponding Author, PhD candidate, Technical University of Košice, Faculty of Economics \\ Email: monika.harcarikova@tuke.sk
}

\author{
Doi:10.5901/mjss.2015.v6n2p303
}

\section{Abstract}

This paper analyses the new structured products formation on the Slovak financial market. Structured products are products, the value of which is derived from the underlying asset value, in our case it is a currency pair (EUR/USD). There are presented Tatra Premium Deposit EKI and new proposed Tatra Premium Deposit EKO from the point of view of its investor and provided detailed descriptions of the profit functions in analytical form. The main objective is to perform an analysis of the classic Tatra Premium Deposit's modification, i.e. Tatra Premium Deposit EKI construction using knock-in barrier option. Then there is proposed new modified product - Tatra Premium Deposit EKO using knock-out barrier option with determination of maximum loss for investor. Finally, there are analysed and compared all three types of Tatra Premium Deposit in EUR for various underlying price development followed by investigation of their profitability with recommendation for potential investors. This analysis is made with the objective to contribute to the intellectualization of all investors.

Keywords: structured products; exotic options; barrier options; payoff profile; currency pair

\section{Introduction}

Structured products, also generally referred as structured investments, have become very popular and significant during the last two decades. As a result of the substantial decline in the interest rates over recent years, the popularity of this new generation of the financial products has risen.

Bluemke (2009) defines structured products as a novel asset class based on derivatives which represent the alternative to a direct investment. Structured products are issued usually by banks with varying features (as terms, returns and risk profiles) of an underlying asset (a financial instrument) which can be a share in a company, a basket of shares, an entire index, commodity or currency. The simplest forms of structured products give investors full or partial capital protection, together with a variable degree of leverage and equity-linked enhanced performance, which are secured by options. They are a portfolio enhancement tool usually used to increase returns while limiting risks of capital loss. Due to structured products, investors can have an access to asset classes that are difficult and expensive to invest in. Structured products have a lot of benefits for investors, which include capital protection, special risk-return profile of the products and diversification. Also the strength of the structured products lies in their flexibility and tailored investment approach. Advatage of the structured products is the limited maximum potential loss by the initial invested amount.

Structured products are designed for each investor according to his/her return requirements, propensity to risk and the market expectations (growth and decline) of the underlying asset development. These products are created by combining underlying asset with derivatives, often option component (classic vanilla and/or exotic option), therefore are connected with the process of financial engineering. Structured products can potentially be highly complicated and difficult to understand for the average investor, but its risk mitigating and customised solutions are definitely very useful, especially if he/she has large investments and need to reduce his/her risk exposure.

Several studies (Benet et al., 2006), (Bluemke, 2009) and (Chorafas, 2006) deal with this modern structured products. And for example in Gordiaková \& Younis (2013), Hernández et al. (2013), Šoltés (2010), Younis \& Rusnáková (2014) authors analyse and explain the various types of investment certificates.

The aim of this paper is to analyse the structured product on the currency pair (EUR/USD) - Tatra Premium Deposit EKI issued by Tatra Bank. This new product represents the modification of classic Tatra Premium Deposit, which 
is offered for investors on the Slovak financial market at present. We explore the application of the financial engineering principles to the structured products creation. It is shown, that this product is formed by using barrier option; specifically European style of up and knock-in call option. Then new product Tatra Premium Deposit EKO with certain conditions is designed using European style of up and knock-out call option with determination of maximum loss for investor. Our approach is focused on the application for structured products with currency pair (EUR/USD) as underlying asset, but the results are robust for various types of currency pairs. There are analysed and compared all three types of Tatra Premium Deposit in EUR for various underlying price development followed by investigation of their profitability with recommendation for potential investors. The analysis will lead to raise the ability of retail investors to understand these sophisticated products constructions.

As it was mentioned early, the structured products are created as a combination of the underlying asset and the options on this underlying asset. Therefore, methodology of this paper must be based on options, which are significant part of the structured products. The profit functions of options, in our case barrier options, are expressed in the analytical expression. Through the presented approach of the analytical expression of the barrier options we can explicitly prove to the nature of the structured products creation. And it is possible to simultaneously propose new structured product.

The paper is organized on the follows sections. In the section two, there are introduced barrier options in general. Third section presents the pricing models of the barrier options which are used on structured products formation. Fourth part analyses Tatra Premium Deposit EKI, its characteristic and creation. In the fifth part we design new product Tatra Premium Deposit EKO with certain conditions which eliminated disadvantages of classic Tatra Premium Deposit and Tatra Premium Deposit EKI. Sixth part applies our approach on the real data on the market with comparison of these products and recommendation for potential investors. The conclusions are summarized in the last section.

\section{Barrier Options Suitable in Structured Products Formation}

Options (classic vanilla or exotic options) are the heart of the most structured products. Zhang (1998) defines a standard option as a financial contract which gives its buyers (holder) the right to buy (call option) or sell (put option) a given amount of the underlying asset (in our case currency pair) at a prespecified price (referred as exercise or strike price) within a prespecified time (referred as time to maturity or time to expiration). The foreign exchange options market belongs to the largest and the most liquid market for options, which is trading on the over the counter market (OTC). Options are flexible tools that appeal to active investors and can be used for speculation or hedging. Hedging by means of options strategies using barrier options is discussed in the work Šoltés \& Rusnáková (2013). In general, options provide a lot of opportunities to modify the risk-return profile of a portfolio.

Exotic options are one of the most interesting innovations of the financial sector in the last years. The term "exotic option" was popularized by Rubinstein \& Reiner (1991). Today exotic options are in the continual development process and are still creating new types of them respectively modifying existing ones. Detailed descriptions of exotic options exist in the literature (Bryis et al., 1998), (Hull, 2008), (Nelken, 1996), (Taleb, 1997), (Weert, 2008) and (Zhang, 1998).

Barrier options are probably the oldest and the most popular type of exotic options contract. They are fairly similar to standard types of vanilla options but with an important additional feature - the barrier. Exceeding the barrier during the option life means activation (knock-in) respectively deactivation (knock-out) of option. The barrier may be over (up) or below (down) the current underlying asset price at the time of closing option contracts. Barrier options are therefore associated with a condition which has to be met, otherwise it will expire as worthless. Their option premiums are always cheaper in comparison to vanilla option premiums due to higher risk which the holder has to take. It can be proved (Haug, 1998), that the sum of knock-in call/put option premium and knock-out call/put option premium is vanilla call/put option premium, if the options are for the identical underlying asset with the identical strike price, the time to maturity and the barrier. In general, the options may be exercised on any trading day before expiration date (referred as American option) or only on expiration date (referred as European option). As a basic rule, if we were expecting significant price movements in the underlying security then we would invest in knock in contracts. However if we were expecting small price movements then we would invest in knock out contracts. There are altogether 16 basic option positions of barrier options with one barrier and slightly different payoff structures. Besides the single barrier options, more exotic variants of barrier options have been formed, such as multi-barrier options. Although they have various characteristics, their nature is the same, it means that their activation and deactivation depend on reaching one or more barriers during the option life.

This paper uses an approach, which is based on the profit functions of the barrier options in the analytical expression, in order to prove the nature of the structured products creation and simultaneously to propose new structured product.

In the construction of Tatra Premium Deposit EKI we are going to use selling of up and knock-in call options. In 
case of new designed Tatra Premium Deposit EKO we are going to use selling of up and knock-out call options.

Selling of European up and knock-in call options gives an obligation to sell a particular underlying at the strike price $X$ at the time $T$ if the option is activated, that is, the underlying price exceed predetermined higher barrier $B$ at the maturity date of the option which is represented by the following condition

$$
\max _{t=T}\left(S_{t}\right) \geq B
$$

For this obligation the seller gains an option premium csu per option at the time of contract conclusion.

Then the profit function of a short position in the number of $n$ up and knock-in call options on the underlying with the strike level $X$, the barrier level $B$, the price at the maturity date $S_{T}$, the premium csul for an option and the time to maturity of the option $t$ is:

$$
P\left(S_{T}\right)= \begin{cases}-n\left(S_{T}-X-c_{S U I}\right) & \text { if } \max _{t=T}\left(S_{t}\right) \geq B \wedge S_{T} \geq X, \\ n c_{S U I} & \text { if } \max _{t=T}\left(S_{t}\right) \geq B \wedge S_{T}<X, \\ n c_{S U I} & \text { if } S_{T}<B .\end{cases}
$$

Selling of European up and knock-out call options gives an obligation to sell a particular underlying at the strike price $X$ at the time $T$ if the option is not deactivated, that is, the underlying price does not exceed predetermined higher barrier $B$ at the maturity date of the option.

The profit function of a short position in the number of $n$ up and knock-out call options on the underlying with the strike level $X$, the barrier level $B$, the price at the maturity date $S_{T}$, the premium csuo for an option and the time to maturity of the option $t$ is:

$$
P\left(S_{T}\right)= \begin{cases}-n\left(S_{T}-X-c_{\text {SUo }}\right) & \text { if } \max _{t=T}\left(S_{t}\right)<B \wedge S_{T} \geq X, \\ n c_{\text {sUo }} & \text { if } \max _{t=T}\left(S_{t}\right)<B \wedge S_{T}<X, \\ n c_{\text {SUo }} & \text { if } S_{T} \geq B .\end{cases}
$$

\section{Pricing of Structured Products through Barrier Options}

The structured products prices can be evaluated through option pricing models. Therefore we introduce theoretical models for option pricing.

Theoretical European vanilla call and put option price on the stocks without dividend is introduced in the work Black \& Scholes (1973). Garman \& Kohlhagen (1983) extended the Black-Scholes model on currency options, where they presented two interest rates - one for each currency. They suppose two risk-free interest rates in the model, i.e. $r_{d}$ is the risk-free interest rate for domestic currency and $r_{f}$ is for the foreign currency.

However, the classical Black \& Scholes (1973) approach does not directly suit barrier options, because the next factor - a barrier influences on height of an option premium. Merton (1973) modified Blach-Scholes model and derived the first relationship to calculate of European down and knock-out call option price. Later Rubinstein \& Reiner (1991) applied Black-Sholes-Merton formula on eight basic types of barrier options and Haug (1998) on all sixteen single types of standard European barrier options. And Rich (1997) provided a mathematical structure to barrier options value.

In order to calculate up and knock-in/up and knock-out call barrier option prices based on Haug (1998) pricing model, we need the maturity dates, the strike prices, the barrier levels, the risk-free interest rates and the implied volatilities. All derived relations for all sixteen single types of standard European barrier options we can find in paper Šturc \& Žoldáková (2011). For the purposes of our analysis, the implied volatility $(\sigma)$ of the underlying is gained for currency pair EUR/USD from Bloomberg. Implied volatility is used to help predict potential movements in the spot market. One of the possibilities used to estimate risk-free interest rate is LIBOR interest rate having the times to maturity match those of the certificates, and which represents the inter-bank lending rate.

Because of the absence of market barrier option data, the values of the position in European style of up and knockin call/up and knock-out call barrier options on the currency pair (EUR/USD) are calculated. All calculations of barrier option prices were implemented in the Bloomberg database.

\section{Analysis of Tatra Premium Deposit EKI}

This paper is focused on new structured product offered on the Slovak market, i.e. Tatra Premium Deposit EKI (referred as TPD EKI) issued by Tatra Bank. It is a deposit product on the underlying asset of currency pair (EUR/USD), which offers extraordinary valorization of free resources in comparison to ordinary term deposit with similar time period. 
Classic Tatra Premium Deposit (referred as TPD) was already investigated in paper (Šoltés \& Rusnáková, 2010), where authors demonstrated the construction of classic Tatra Premium Deposit on currency pair EUR/PLN by selling vanilla call option at the strike price $X$ equals to reference price RP. TPD offers higher interest on funds but bears risk that upon maturity the funds can be disbursed in a different currency than the original deposit currency if the underlying price increases above the strike price.

TPD product is more risky in the case of underlying price increasing in comparison to new product TPD EKI. In this case, it is sufficient if the exchange rate is higher than the strike price $X$ for disbursement of fund in a different currency. Following the mentioned study we realize more comprehensive analysis for this new structured product.

TPD EKI is suitable for those investors who accept to exchange their available resources into another currency at certain exchange rate. Also in the case of conversion at the maturity date of deposit, they are willing to wait for their expected level of exchange rate. All products are tailored to clients' needs.

New currency and exchange rate will be agreed during the deal making. Product offers significantly higher interest on deposit, which is available also for shorter periods (e.g. a month). TPD EKI is more conservative product compared to TPD due to European knock-in barrier level set above the reference price. If the barrier level $B$ is touches or even crosses at the maturity date (referred as ending date or expiration date) $T$, the issuer (the bank) can exchange the investor's deposit into alternative currency at the agreed reference price.

Client (investor) deposits his/her free resources in Currency 1 (in our case EUR), referred as main currency and simultaneously chooses Currency 2 (in our case USD), referred as secondary/alternative currency at the agreed time to maturity at the guaranteed interest.

In the issue date of the product there is known the higher knock-in barrier $B$ and the reference price $R P$ (known as the strike price/the exercise price $X$ ).

There can be two variants of underlying price development depending on exceeding or not exceeding of the barrier. If the underlying price (EUR/USD) is above the knock-in barrier (in the case of deposit in EUR) or below the knock-in barrier (in the case of deposit in USD) at the maturity date $T$, then the bank exchange the investor's deposit into alternative currency at the agreed reference price. If the underlying price is not exceeded at the maturity date $T$, then the bank will pay to investor his/her original currency deposit back. The interest return will be always paid investor in original currency deposit.

The payoff profile of the deposit in Currency 1 (EUR) with the nominal value $N V$, the reference price $X$, the price at the maturity date $S_{T}$, the time to maturity $t$, the interest $I$, the barrier level $B$ at the maturity date $T$ is:

$$
P\left(S_{T}\right)= \begin{cases}N V_{E U R}+I_{E U R} & \text { if } \max _{t=T}\left(S_{t}\right)<B, \\ N V_{E U R} * \frac{X}{S_{T}}+I_{E U R} & \text { if } \max _{t=T}\left(S_{t}\right) \geq B,\end{cases}
$$

Then the profit profile is expressed as

$$
P\left(S_{T}\right)= \begin{cases}I_{E U R} & \text { if } \max _{i \in T}\left(S_{t}\right)<B, \\ N H_{E U R} *\left(\frac{X}{S_{T}}-1\right)+I_{E U R} & \text { if } \max _{t \in T}\left(S_{t}\right) \geq B,\end{cases}
$$

Product TPD EKI is connected with risk (i.e. currency risk, interest risk, volatility risk, etc.) of loss invested capital. In the case of underlying price growth above the barrier $B$ investor can lose the whole his/her deposit amount. It is less risky than classic TPD, where the loss is increasing if the underlying price is above the reference price $X$.

\subsection{Nature of the creation}

Now let look at it how issuer (the bank) can create product TPD EKI.

In the time To issuer (the bank):

- sells a product (TPD EKI) at the nominal value (NV),

- sells European up and knock-in call option with a strike price $X=R P$, a barrier defined above the reference price, i.e. $B>R P$ and the premium csuper option,

- the amount $\left(N V+c_{S U I}\right)$ is deposited at interest rate $r_{1}$ to the time of product's expiration.

There are two possibilities in the time $T$, i.e. in the time to maturity of the product equals the time to maturity of the up and knock-in call option.

If there is $S_{T}<B$, the option is worthless therefore the bank has no duties and pay to investor his/her original currency deposit back. 
Or if there is $S_{T} \geq B$, then issuer (the bank) have to sell buyer's option Currency 1 (EUR) for Currency 2 (USD) at the exchange rate $X=R P$. The bank pays the buyer of the product (investor) the amount $N V^{*} X$. Investor can exchange back his/her payoff in Currency 2 (USD) at Currency 1 (EUR) at exchange rate $S_{T}$.

Let us denote nominal value of the product NV, option premium for selling up and knock-in call barrier option csul, interest rate per year $r_{1}$ and time to expiration $T$, then issuer (the bank) gains guaranteed return in the amount of

$\left(N V+c_{S U I}\right) * r_{1} * \frac{T}{360}$

If issuer guarantee the buyer's product interest rate per year $r$, then there must be fulfilled the following condition:

$$
\left(N V+c_{S U I}\right) * r_{1} * \frac{T}{360} \geq N V * r * \frac{T}{360}
$$

where

$$
r \leq \frac{\left(N V+c_{S U I}\right) * r_{1}}{N V}
$$

which guarantee interest rate paid for buyers of product.

Product TPD EKI is more advantageous in comparison to classic TPD product, therefore Currency 1 is exchanged for Currency 2 only in the case of exceeding the barrier in the time of product's expiration. Due to the barrier, TPD EKI is less risky as classic TPD product, but the losses of both products are unlimited. If the barrier is situated closer to the reference price, the investor undergoes higher risk but also gains higher return and vice versa.

In case of the classic TPD and TPD EKI, the investor can lose a lot from his/her deposit amount. The loss increases quickly for classic TPD product and its modification TPD EKI if the exchange rate increases above the reference price $X$ or the barrier $B$. This is the main disadvantage of these products, therefore they are appropriate mainly in the time of low volatility. Our aim is to design new product which eliminate this disadvantage (unlimited loss) in the section 5 .

\section{Design of New Type of Tatra Premium Deposit EKO}

In this section, we propose new modified TPD product - Tatra Premium Deposit EKO (referred as TPD EKO) with determination of maximum loss for investor.

Creation of TPD EKO product is with using up and knock-out call option. In this product the higher knock-out barrier $B$ is set again above the reference price RP. Up and knock-out call barrier option is deactivated if the barrier is reached or exceeded. There are three variants of underlying price development at the maturity date $T$.

If the underlying (the exchange rate) is at or above the barrier level at the maturity date, Currency 1 (EUR) is not exchanged for Currency 2 (USD).

If the underlying (the exchange rate) is below the barrier level but above the reference level at the maturity date, Currency 1 (EUR) is exchanged for Currency 2 (USD) at the reference price.

The payoff profile of the deposit in Currency 1 (EUR) with the nominal value $N V$, the reference price $X$, the price at the maturity date $S_{T}$, the time to maturity $t$, the interest $I$, the barrier level $B$ at the maturity date $T$ is:

$$
P\left(S_{T}\right)= \begin{cases}N V_{E U R}+I_{E U R} & \text { if } \max _{t=T}\left(S_{t}\right) \geq B, \\ N V_{E U R} * \frac{X}{S_{T}}+I_{E U R} & \text { if } \max _{t=T}\left(S_{t}\right)<B \wedge S_{T} \geq X, \\ N V_{E U R}+I_{E U R} & \text { if } \max _{t \in T}\left(S_{t}\right)<B \wedge S_{T}<X,\end{cases}
$$

Then the profit profile is expressed as

$$
P\left(S_{T}\right)= \begin{cases}I_{E U R} & \text { if } \max _{t=T}\left(S_{t}\right) \geq B, \\ N V_{E U R} *\left(\frac{X}{S_{T}}-1\right)+I_{E U R} & \text { if } \max _{t \in T}\left(S_{t}\right)<B \wedge S_{T} \geq X, \\ I_{E U R} & \text { if } \max _{t=T}\left(S_{t}\right)<B \wedge S_{T}<X,\end{cases}
$$

There is an exchange of Currency 1 (EUR) for Currency 2 (USD) more probably for this new proposed product, but exchange of currencies back without loss is higher in the nearest future. Investor can wait on his/her expected exchange rate. However, the immediate loss is limited by value:

$$
N V-\frac{N V * X}{B}=N V\left(1-\frac{X}{B}\right)
$$




\subsection{Nature of the creation}

The principle of this new proposed product TPD EKO is simple and is focused on limiting the maximum loss.

In the time $T_{0}$ issuer (the bank):

- sells a product (TPD EKO) at nominal value (NV),

- sells European up and knock-out call option with a strike price $X=R P$, a barrier defined above the reference price, i.e. $B>R P$ and the premium csuo per option,

- the amount $\left(N V+c_{S U O}\right)$ is deposited at interest rate $r_{1}$ to the time of product's expiration.

There are three possibilities in the time $T$, i.e. in the time of product's expiration which is the same as up and knock-out call option expiration.

If the underlying price (the exchange rate) at the maturity date $S_{T}$ is above the reference price $X$ and below the

barrier $B$ in time $T$, i.e. $X<S_{T}<B$, then issuer (the bank) sells buyer's option Currency 1 (EUR) for Currency 2 (USD) at the exchange rate $X=R P$, i.e. the amount $N V^{*} X$ is paid the buyer of the product (investor). Investor can exchange back secondary currency (Currency 2 ) at main currency (Currency 1 ) at the exchange rate $S_{T}$, which is certainly below the barrier $B$, therefore his/her loss is limited.

If the underlying price (the exchange rate) at the maturity date $S_{T}$ is below the reference price $X$ or above the barrier $B$ in time $T$, then investor gets back the nominal value NV in main currency (Currency 1 ) and the interest return, therefore the barrier option is deactivated and the bank has no duties to sell main currency.

Let's assume, the nominal value of the product is referred $N V$, option premium for selling up and knock-out call barrier option csuo, interest rate per year $r_{1}$ and time to expiration $T$, then the interest rate per year $r$ for investor is again calculated according to equation:

$$
r \leq \frac{\left(N V+c_{S U O}\right) * r_{1}}{N V}
$$

Our proposed TPD EKO product has the advantage compared to existing products, TPD respectively TPD EKI, on the Slovak market, which is limited investor's loss. Due to limited loss, TPD EKO is an interesting opportunity for more conservative investors in the time of hight volatility of currency.

\section{Application on the Real Data on the Market}

In this section, we present real product TPD EKI offered on the Slovak market on $3^{\text {th }}$ September 2014. The key stylized data about the structured product is in the Table 1. Due to simplification, we apply data from the Table 1 for the prices of classic TPD product and our proposed TPD EKO product and compare given products from the point of their profitability for to the investor at the time of maturity. We will use European style vanilla and barrier options on currency pair (EUR/USD) on the creation of these structured products.

Table 1. The basic characteristics of Tatra Premium Deposit EKI on $3^{\text {th }}$ September 2014

\begin{tabular}{|l|c|}
\hline Underlying & EUR/USD \\
\hline Main currency & EUR \\
\hline Secundary currency & USD \\
\hline Nominal value & EUR 100.00 \\
\hline Relevant price & 1.3151 \\
\hline Barrier & 1.3300 \\
\hline Relevant date & $03 / 09 / 2014$ \\
\hline Maturity date & $17 / 09 / 2014$ at $17: 00$ \\
\hline Interest rate & $5 \%$ p.a. \\
\hline
\end{tabular}

Source: Own design

Investor buys the structured product TPD EKI at the nominal value 100.00 EUR. Then two weeks interest equals to 0.19 EUR (present $5 \%$ p.a.), which the bank guarantees the investor at the time of maturity. At maturity date of the given certificate may occur 2 scenarios of payment depending on exceeding or not exceeding the barrier 1.33 EUR/USD. According to relation (4), the payoff profile of the TPD EKI in EUR at the maturity date $T$ is represented by the following 
equation:

$$
P\left(S_{T}\right)= \begin{cases}100.19 \text { EUR } & \text { if } \max _{t=T}\left(S_{t}\right)<1.33, \\ \frac{131.51 U S D}{S_{T}}+0.19 E U R & \text { if } \max _{t=T}\left(S_{t}\right) \geq 1.33,\end{cases}
$$

The bank sets the interest rate for the TPD EKI for the investor based on (8). If the bank sells up and knock-in call barrier option to buy 100.00 EUR for USD at the strike price 1.3151 at the time T, which is identical to the time to maturity of the structured product, then the bank will get $c_{S U I}$ for each option, i.e. in total $100 * c_{S U I}$ EUR. As a result of its, the sale of the option will be an obligation to sell 100.00 EUR for 1.3151 USD, where the price at the maturity date will be greater or at least equal than 1.3300. The financial institution (or the bank) is responsible for paying back the investors's capital together with the return at the end of the investment time. If the bank wants to determine the interest rate for TPD EKI without risk, the bank has to receive the nominal value of the product 100.00 EUR and enought premium from the sale of up and knock-in call barrier option. In our case the bank sells up and knock-in call barrier option at least for ${ }^{c_{S U O}}=0.00194$ EUR per option, where parameters introduce the starting price 1.3151, the barrier 1.33 , the risk-free interest rate $0.038 \%$ and the implied volatility $0.157 \%$ gained from the Bloomberg. Received resources let interest at the same time as the time to maturity of the structured product. Only in this case the bank can determine the interest rate for TPD EKI of 5.00\% without risk.

Let us propose classic TPD and modified TPD EKO products with application on data from the Table 1. Then the payoff profile (Šoltés \& Rusnáková, 2010) of the classic TPD in EUR at the maturity date $T$ is

$$
P\left(S_{T}\right)= \begin{cases}100.19 \mathrm{EUR} & \text { if } S_{T}<1.3151, \\ \frac{131.51 \mathrm{USD}}{S_{T}}+0.19 \mathrm{EUR} & \text { if } S_{T} \geq 1.3151,\end{cases}
$$

According to relation (9), the payoff profile of the TPD EKO in EUR at the maturity date is represented by the following equation:

$$
P\left(S_{T}\right)= \begin{cases}100.19 \mathrm{EUR} & \text { if } \max _{\substack{t=T \\(31.51 U S D}}\left(S_{t}\right) \geq 1.33, \\ 100.19 \mathrm{EUR} & \text { if } \max _{t=T}\left(S_{t}\right)<1.33 \wedge S_{T} \geq 1.3151, \\ \text { if } \max _{t=T}\left(S_{t}\right)<1.33 \wedge S_{T}<1.3151,\end{cases}
$$

At the maturity date the maximum loss (11) from the TPD EKO product is $100\left(1-\frac{1.3151}{1.33}\right)=1.12$ without adding the interest return.

Finally, we evaluate the profitability analysis for the given structured products at the maturity date $17^{\text {th }}$ September 2014. The profit from the given structured products for the selected underlying price at the maturity date is in the Table 2.

Table 2. Comparison of the profitability (in EUR) of the modifications of Tatra Premium Deposit

\begin{tabular}{|c|c|c|c|}
\hline \multirow{2}{*}{ The underlying price at the maturity date $\mathbf{S}_{\boldsymbol{T}}$} & \multicolumn{3}{|c|}{ The profit / loss } \\
\cline { 2 - 4 } & TPD & TPD EKI & TPD EKO \\
\hline 1.3000 & 0,1900 & 0,1900 & 0,1900 \\
\hline 1.3151 & 0,1900 & 0,1900 & 0,1900 \\
\hline 1.3200 & $-0,1812$ & 0,1900 & $-0,1812$ \\
\hline 1.3250 & $-0,5572$ & 0,1900 & $-0,5572$ \\
\hline 1.3300 & $-0,9303$ & $-0,9303$ & 0,1900 \\
\hline 1.3400 & $-1,6682$ & $-1,6682$ & 0,1900 \\
\hline 1.3500 & $-2,3952$ & $-2,3952$ & 0,1900 \\
\hline
\end{tabular}

Source: Own design

The results indicate from the Table 2, that all three products gain fixed interest 0.19 EUR if the underlying price (the exchange rate) at the maturity date is lower than the strike price 1.3151. However, if the underlying price at the maturity date rises above the strike price 1.3151, classic TPD product and TPD EKO product start to lose due to conversion to USD at the strike price. In case of classic TPD product is loss unlimited and TPD EKO product is loss limited. The loss from the product TPD EKI is unlimited if the underlying price rises above the barrier 1.3300. If there is conversion EUR to USD, then in case of the classic TPD product and the TPD EKI product investor has to wait longer on his/her expected 
exchange rate than in case of TPD EKO product.

Based on the performed analysis and comparison of certificates we have the following findings. If the investor expects bigger decrease in the underlying price, he/she should choose one of the TPD product's type depending on the higher interest. Further, we can conclude that if there is expected weak volatility, then TPD EKI product is suitable for investment. However, if there is expected strong volatility, TPD EKO product is more suitable for investment.

Products classic TPD and TPD EKO are only theoretical expamples. In practice the interest rate should be the highest for classic TPD product, then it would follow product TPD EKI. Product TPD EKO should have the lower interest rate due to lower risk incurred. But finally, the choice between these products is depended on the investor's personal view.

\section{Conclusion}

Today structured products are gaining on popularity and still more and more investors are adding these products to their portfolios due to interesting risk-return profiles. It can be seen that structured products definitely bring a level of sophistication and benefits to various types of investors. Such products offer different strategies according to the preferences of the investor, such that the products can be truly customised to their needs.

This paper aims at showing the nature of the formation of structured product offered on the Slovak financial market - Tatra Premium Deposit EKI (modification of classic Tatra Premium Deposit product) issued by Tatra Bank. Further there is designed new structured product - Tatra Premium Deposit EKO with certain conditions for determination of maximum loss for investor. The selection of these products for the analysis was made with the objective to show a possibility of using European barrier options in the structured products formation.

Our approach is focused on the application for modification of Tatra Premium Deposit with underlying asset (currency pair EUR/USD), but the results are robust for various types of currency pairs. We analyse and compare all three types of Tatra Premium Deposit in EUR for various underlying price development followed by investigation of their profitability with recommendation for potential investors. This analysis was made with the objective to contribute to the intellectualization of an investor.

This approach is based on of the profit functions for barrier options in the analytical expression, which are significant part of every structured product. From the methodological point of view, our analysis can serve as an inspiration for a further structured products formation using American barrier options.

\section{References}

Benet, B. A., Giannetti, A., \& Pissaris, S. (2006). Gains from structured product markets: The case of reverse-exchangeable securities (RES). Journal of Banking and Finance, 30(1), 111-132.

Black, F., \& Scholes, M. (1973). Pricing of Options and The Corporate Liabilities. Journal of Political Economy, 81(3), 637-654.

Bluemke, A. (2009). How to Invest in Structured Products: A Guide for Investors and Investment Advisors. Chichester, West Sussex, U.K.: Wiley.

Bryis, E. et al. (1998). Options, Futures and Exotic Derivatives: Theory, Application and Practice. New York: Wiley \& Sons, Inc.

Garman, M. B. and Kohlhagen, S. W. (1983). Foreign currency option values. Journal of International Money and Finance, 2, $231-237$.

Gordiaková, Z., \& Younis, A. M. A. (2013). Proposal of a new guaranteed certificate using exotic options. Journal of Applied Economic Sciences, 8(2), 191-197.

Haug, E. (1998). The Complete Guide to Option Pricing Formulas. Hardcover: McGraw-Hill.

Hernández, R., Lee W. Y., Liu, P., \& Dai, T. S. (2013). Outperformance Certificates: analysis, pricing, interpretation, and performance. Springer US: Review of Quantitative Finance and Accounting, 40(4), 691-773.

Hull, J. C. (2008). Options, Futures and Other Derivatives. (7th ed.). New Jersey: Pearson Prentice Hall.

Chorafas, D. N. (2006). Wealth Management: Private Banking, Investment Decisions and Structured Financial Products. Hardcover: Elsevier Ltd.

Merton, R.C. (1973). Theory of rational option pricing. Journal of Economics and Management Science, 4(1), 141-183.

Nelken, I. (1996). The handbook of exotic options: Instruments, analysis, and applications. New York: Mc Graw-Hill.

Rich, D. (1997). The mathematical foundations of barrier option pricing theory. Advances in futures and options research : a research annual, 7, 267-312.

Rubinstein, M., \& Reiner, E. (1991). Breaking Down the Barriers. Journal of Risk, 4(8), 28-35.

Šoltés, M. (2010). Relationship of speed certificates and inverse vertical ratio call back spread option strategy. E+M Ekonomie a Management, 13(2), 119-124.

Šoltés. V., \& Rusnáková. M. (2010). Utilization of options in the formation of structured products. Transactions of the Universities of Kosice, No.1, 65-72. 
Šoltés, V., \& Rusnáková, M. (2013). Hedging Against a Price Drop Using the Inverse Vertical Ratio Put Spread Strategy Formed by Barrier Options. Inzinerine Ekonomika - Engineering Economics, 24(1), 18-27.

Šturc, B., \& Žoldákova, N. (2011). Oceňovanie bariérových opcií a ich využitie. In: Hradecké ekonomické dny 2011: Ekonomický rozvoj a management regionu. Hradec Králové: Gaudeamus, Univerzita Hradec Králové, Díl I., 347-351.

Taleb, N. (1997). Dynamic hedging. Managing vanilla and exotic options. (2nd ed.). Hardcover: John Wiley \& Sons, Ltd.

Weert, D. F. (2008). Exotic Options Trading. John Wiley \& Sons, Ltd.

Younis, A. M. A., \& Rusnáková, M. (2014). Formation of the new types of bonus certificates. Actual Problems of Economics, 152(2), 367375.

Zhang, P. G. (1998). Exotic options. (2nd ed.). Singapore: World Scientific Publishing Co.Pte.Ltd. 